\title{
HESITANT FUZZY MULTI-CRITERIA DECISION MAKING METHODS BASED ON HERONIAN MEAN
}

\author{
Dejian YU \\ School of Information, Zhejiang University of Finance and Economics, 310018 Hangzhou, China
}

Received 14 August 2013; accepted 18 May 2014

\begin{abstract}
Among several extensions of fuzzy set theory, the concept introduced by Torra and Narukawa (2009) in defining hesitant fuzzy set is interesting and practical. In this paper we introduce and study new methods for dealing with MCDM (multi-criteria decision making) problems under the hesitant fuzzy environment. First, we propose and discuss the notion of hesitant fuzzy Heronian mean operators. By using these operators, we can portray the relationship of the criteria effectively. Then, the numerical examples are provided and comparative analyses with other aggregation operators are not neglected. Furthermore, the weighted forms of the hesitant fuzzy Heronian mean operators are defined for MCDM problem, based on which, new MCDM methods are proposed. The MCDM methods presented in this paper can provide an effective manner to assist the decision maker in making his/her decision. An example about dormitory construction projection selection is given to show the effectiveness of the proposed method.
\end{abstract}

Keywords: hesitant fuzzy set, multi-criteria decision-making, Heronian mean.

JEL Classification: C43, D81.

\section{Introduction}

Torra and Narukawa (2009) developed the concept of hesitant fuzzy set (HFS), which is an extension of fuzzy set, characterized by the membership function expressed by a set of some possible values between [0,1]. HFS is an effective tool in expressing the fuzziness in the daily life of the human beings (Zhang, Xu 2012). The starting point for proposing the theory of HFS is that it is sometimes not easy to decide the degree of the membership of an element belonging to a set, however, this dilemma can be covered by a set of possible values between [0,1] (Zhu, Xu 2013a; Liao et al. 2014). The relationship between HFS and some other extended fuzzy set, such as intuitionistic fuzzy set (Atanassov 1986), Type-2 fuzzy set (Dubois, Prade 1980; Miyamoto 2005) and fuzzy multiset (Yager 1986; Miyamoto 2000)

Corresponding E-mail:

yudejian62@126.com 
are also discussed in detail by Torra and Narukawa (2009). Furthermore, Torra (2010) have pointed out that the envelope of HFS is an intuitionistic fuzzy set.

In the past few years, HFS theory has been receiving extensively attention from various aspects, including interval-valued HFS (IVHFS) (Chen et al. 2013; Farhadinia 2013; Quirós et al. 2015), entropy measures and cross-entropy (Xu, Xia 2012), distance and similarity measures (Zhu, Xu 2014; Xia, Xu 2011a; Xu, Xia 2011). Since its powerfulness in dealing with vagueness, HFS theory has been received many application achievements, such as personnel evaluation, medical diagnosis, clustering analysis, pattern recognition, and MCDM. In order to obtain the most suitable candidate in MCDM problem, aggregating the experts' evaluations on each criterion for different alternatives is a very important step (Xu, Zhang 2013; Parameshwaran et al. 2015). In other words, aggregation methods are indispensable to MCDM problems (Karsak, Dursun 2015; Liu et al. 2015).

Learned from the idea of intuitionistic fuzzy aggregation operators, Xia and $\mathrm{Xu}(2011 \mathrm{~b})$ first proposed many operators for hesitant fuzzy elements (HFEs), such as hesitant fuzzy weighted averaging (HFWA) operator, HFWG, GHFWA and GHFWG operators. Based on the research results of Xia and Xu (2011b), Wei et al. (2012) introduced some subjective correlated aggregation operators called Choquet aggregation operators. With the aid of quasi-arithmetic means, Xia et al. (2013) introduced the generalized form of hesitant fuzzy aggregation operators. Zhu et al. (2012) introduced some objective correlated aggregation operators called geometric Bonferroni means operators and hesitant fuzzy Bonferroni means operators respectively.

Compared with Bonferroni mean (Bonferroni 1950), Heronian mean (HM) (Beliakov et al. 2007) is another aggregation technique which can also depict the relationship between aggregated arguments objectively. From the definitions of Bonferroni mean and HM, we find that the BM mainly indicated the correlations between any pairs of $c_{i}$ and $c_{j}(i \neq j)$. However, it should be pointed out that the correlation between $c_{i}$ and $c_{j}(i \neq j)$ is exactly the same with the correlation between $c_{j}$ and $c_{i}(i \neq j)$. In other words, the BM operator takes into account it twice and it generates redundant subsequently. HM can deal with this situation effectively although it has a similar structure with BM. At present, the HM has been applied to intuitionistic fuzzy environment (Yu 2013) rather than any other kinds of arguments, such as hesitant fuzzy environment and this is the focus of this paper.

To do this, the rest of this study is organized as follows: in Section 1, we review some concepts such as HFS theory associated with our research. In Section 2, we propose the hesitant fuzzy Heronian mean operator (HFHM) and the hesitant fuzzy geometric Heronian mean operator (HFGHM) the weighted form of HFHM and HFGHM operators are also proposed in this section. A MCDM method based on the proposed operator is forwarded in the context of hesitant fuzzy environment in Section 3. A comparative example is presented for finding correlations with hesitant fuzzy BM operators ( $\mathrm{Zhu}, \mathrm{Xu} 2013 \mathrm{~b}$; Zhu et al. 2012) and shows the applicability of the proposed MCDM approach. The last Section gives some conclusion remarks. 


\section{Some basic concepts}

Decision makers always face the actual conditions which is vagueness and uncertainty. There exist various techniques to cope with the vagueness and uncertainty phenomenon; however, different techniques are designed for different situations.

Definition 1 (Torra, Narukawa 2009; Xia et al. 2013). Let $X$ be an any given set, a HFS is a mathematical function that when refer to $X$ it returns a subset belongs to $[0,1]$, and it can be showed as follows:

$$
E=\left\{<x, h_{E}(x)>\mid x \in X\right\},
$$

where $h_{E}(x)$ is a group of some possible numbers in $[0,1]$.

Operations on the HFEs are very basic for HFS theory. Xia and Xu (2011b) have studied on this and achieved some research results as follows:

Definition 2. Let $h, h_{1}$ and $h_{2}$ be three HFEs, then
1) $h^{\lambda}=\bigcup_{\xi \in h}\left\{\xi^{\lambda}\right\}, \lambda>0$;
2) $\lambda h=\bigcup_{\xi \in h}\left\{1-(1-\xi)^{\lambda}\right\}, \lambda>0$;
3) $h_{1} \oplus h_{2}=\bigcup \xi_{1} \in h_{1}, \xi_{2} \in h_{2}\left\{\xi_{1}+\xi_{2}-\xi_{1} \xi_{2}\right\}$;
4) $h_{1} \otimes h_{2}=\bigcup_{\xi_{1} \in h_{1}, \xi_{2} \in h_{2}}\left\{\xi_{1} \xi_{2}\right\}$.

In the above operations, $\lambda$ is a real number greater than zero. Xia and Xu (2011b) introduced the following comparative method.

Definition 3. Suppose $h$ is a given HFE, the score of $h$ is defined as $S(h)=\frac{1}{\# h} \sum_{\xi \in h} \xi$, and \# $h$ is used to represent the number of the elements in HFE $h$. For any given two HFEs $h_{1}$ and $h_{2}$, if $S\left(h_{1}\right)>S\left(h_{2}\right)$, then $h_{1}$ is better than $h_{2}$ and expressed as $h_{1} \succ h_{2}$; if $S\left(h_{1}\right)=S\left(h_{2}\right)$, then $h_{1}$ is equal to $h_{2}$ and expressed as $h_{1} \sim h_{2}$.

\section{HFHMs}

In this section we study the Heronian mean aggregation method and introduce the HFHMs, the properties of the proposed operators are also discussed in this Section.

Beliakov et al. (2007) introduced the basic Heronian mean operator as follows:

Definition 3. Let $a_{i}(i=1,2, \ldots, n)$ be a set of real numbers which are greater than zero. If

$$
\operatorname{BHM}\left(a_{1}, a_{2}, \ldots, a_{n}\right)=\frac{2}{n(n+1)} \sum_{i=1}^{n} \sum_{j=i}^{n} \sqrt{a_{i} a_{j}},
$$

then $B H M$ is named as Basic Heronian mean.

Based on Definition 3, Yu and Wu (2012) extended the BHM to a more generalized form by introducing two parameters $p$ and $q$.

Definition 4. Suppose there are two parameters $p$ and $q(p>0, q>0)$, and $a_{i}(i=1,2, \ldots, n)$ be a set of nonnegative real numbers. If 


$$
\operatorname{HM}^{p, q}\left(a_{1}, a_{2}, \ldots, a_{n}\right)=\left(\frac{2}{n(n+1)} \sum_{i=1}^{n} \sum_{j=i}^{n} a_{i}^{p} a_{j}^{q}\right)^{1 / p+q},
$$

then $H M$ is called the Heronian mean. 2007).

It should be noted that, when $p=q=\frac{1}{2}$, the HM reduces to the BHM (Beliakov et al.

Definition 5. Suppose there is a set of HFEs $h_{j}(i=1,2, \ldots, n)$, the HFHM is defined as follows:

$$
\operatorname{HFHM}\left(h_{1}, h_{2}, \cdots, h_{n}\right)=\left(\frac{2}{n(n+1)} \sum_{i=1}^{n} \sum_{j=i}^{n} h_{i}^{p} \otimes h_{j}^{q}\right)^{1 / p+q} .
$$

Especially, if $p=q=\frac{1}{2}$, then the HFHM operator reduces to the basic HFHM (BHFHM):

$$
\operatorname{BHFHM}\left(h_{1}, h_{2}, \cdots, h_{n}\right)=\frac{2}{n(n+1)} \sum_{i=1}^{n} \sum_{j=i}^{n} \sqrt{h_{i} \otimes h_{j}} .
$$

Theorem 1. Suppose there are two parameters $p$ and $q(p>0, q>0)$, and $h_{j}(i=1,2, \ldots, n)$ be a set of HFEs, then the aggregated value by using the HFHM is as follows:

$$
\operatorname{HFHM}\left(h_{1}, h_{2}, \ldots, h_{n}\right)=\bigcup_{\xi_{i} \in h_{i}, \xi_{j} \in h_{j}}\left\{\left(1-\prod_{i=1, j=i}^{n}\left(1-\xi_{i}^{p} \xi_{j}^{q}\right)^{\frac{2}{n(n+1)}}\right)^{\frac{1}{p+q}}\right\} \text {. }
$$

Proof. According to the operations defined in Definition 2, we know:

$$
h_{i}{ }^{p}=\bigcup_{\xi_{i} \in h_{i}}\left\{\xi_{i}{ }^{p}\right\}, h_{j}^{p}=\bigcup_{\xi_{j} \in h_{j}}\left\{\xi_{j}{ }^{p}\right\}
$$

and

$$
h_{i} p \otimes h_{j}^{q}=\bigcup_{\xi_{i} \in h_{i}, \xi_{j} \in h_{j}}\left\{\xi_{i} p \xi_{j} p\right\},
$$

then

and

$$
\sum_{i=1}^{n} \sum_{j=i}^{n} h_{i}^{p} \otimes h_{j}^{q}=\bigcup_{\xi_{i} \in h_{i}, \xi_{j} \in h_{j}}\left\{1-\prod_{i=1, j=i}^{n}\left(1-\xi_{i}^{p} \xi_{j}^{q}\right)\right\}
$$

$$
\frac{2}{n(n+1)} \sum_{i=1}^{n} \sum_{j=i}^{n} h_{i} p \otimes h_{j}^{q}=\bigcup_{\xi_{i} \in h_{i}, \xi_{j} \in h_{j}}\left\{1-\prod_{i=1, j=i}^{n}\left(1-\xi_{i}^{p} \xi_{j}^{q}\right)^{\frac{2}{n(n+1)}}\right\} .
$$

Therefore, we have:

end.

$$
\operatorname{HFHM}\left(h_{1}, h_{2}, \ldots, h_{n}\right)=\bigcup_{\xi_{i} \in h_{i}, \xi_{j} \in h_{j}}\left\{\left(1-\prod_{i=1, j=i}^{n}\left(1-\xi_{i}^{p} \xi_{j}^{q}\right)^{\frac{2}{n(n+1)}}\right)^{\frac{1}{p+q}}\right\},
$$


When the parameters $p$ and $q$ take different values, some exceptions of the HFGHM can be calculated as follows:

Case 1. If $p=q=\frac{1}{2}$, then the HFHM changes to:

which is the BHFHM.

$$
\operatorname{HFHM}\left(h_{1}, h_{2}, \ldots, h_{n}\right)=\bigcup_{\xi_{i} \in h_{i}, \xi_{j} \in h_{j}}\left\{1-\prod_{i=1, j=i}^{n}\left(1-\sqrt{\xi_{i} \xi_{j}}\right)^{\frac{2}{n(n+1)}}\right\},
$$

Case 2. If $q \rightarrow 0$ then the HFHM operator changes to:

$$
\lim _{q \rightarrow 0} \operatorname{HFHM}\left(h_{1}, h_{2}, \ldots, h_{n}\right)=\left(\frac{1}{n} \sum_{i=1}^{n} h_{i}^{p}\right)^{\frac{1}{p}}=\bigcup_{\xi_{i} \in h_{i}}\left\{\left(1-\prod_{i=1}^{n}\left(1-\xi_{i}^{p}\right)^{\frac{1}{n}}\right)^{\frac{1}{p}}\right\}
$$

which is the generalized hesitant fuzzy weighted operator which has been studied by Xia and $\mathrm{Xu}(2011 \mathrm{~b})$.

Case 3. If $q \rightarrow 0$ and $p=1$, then the HFHM changes to:

$$
\operatorname{HFHM}\left(h_{1}, h_{2}, \ldots, h_{n}\right)=\frac{1}{n}\left(\bigoplus_{i=1}^{n} h_{i}\right)=\bigcup_{\xi_{i} \in h_{i}}\left\{1-\prod_{i=1}^{n}\left(1-\xi_{i}\right)^{\frac{1}{n}}\right\},
$$

which is the hesitant fuzzy average mean operator studied by Xia and Xu (2011b).

Example 1. Let $h_{1}=\{0.1,0.2,0.3\}, h_{2}=\{0.8\}, h_{3}=\{0.4,0.5\}$ be three HFEs, then by Definitions 5 and Theorem 1 , when the parameters take different values, the aggregated HFEs be calculated, for example,

When $p=1, q=1, \operatorname{HFHM}\left(h_{1}, h_{2}, h_{3}\right)=\{0.4987,0.5285,0.5187,0.5478,0.5411,0.5694\}$, and the score of the HFE is 0.5340 .

When $p=3, q=7, \operatorname{HFHM}\left(h_{1}, h_{2}, h_{3}\right)=\{0.6726,0.6749,0.6734,0.6757,0.6757,0.6780\}$, and the score of the HFE is 0.6751 .

If we let one of the values of one parameters fixed, take $p=2$ or $q=2$ for example, the change trends of scores of the aggregated HFEs obtained by HFHM are shown in Figure 1.

On the other hand, Figure 2 described the change trends of scores obtained by HFHM operator when one of the two parameters getting bigger slowly.

Different scores of the HFEs aggregated by HFHM can be calculated as the parameters $p$ and $q$ changed. Figure 3 illustrates the scores obtained by the HFHM operator in detail.

Geometric mean is an important aggregation method and has attracted many attentions from scholars (Liu, Jin 2012; Tan 2011; Wang, Liu 2011; Wei 2010; Xu 2000; Yu 2012). Next, we focus on the geometric form of HFHM operator and introduce the hesitant fuzzy geometric Heronian mean operator (HFGHM).

Definition 6. Suppose there are a group of HFEs $h_{j}(i=1,2, \ldots, n)$. If

$$
\operatorname{HFGHM}\left(h_{1}, h_{2}, \cdots, h_{n}\right)=\frac{1}{p+q}\left(\underset{i=1, j=i}{\otimes}\left(p h_{i} \oplus q h_{j}\right)^{2 / n(n+1)}\right),
$$

then HFGHM is called the HFGHM. 


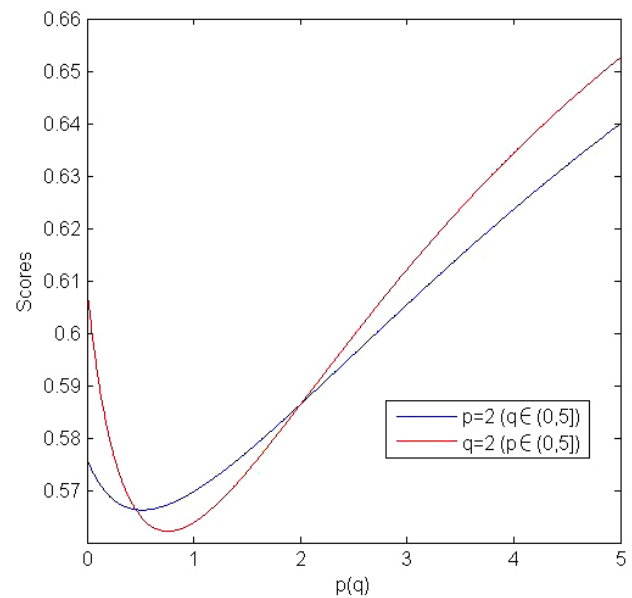

Fig. 1. Change trends of the Scores $p=2$ and $q=2$
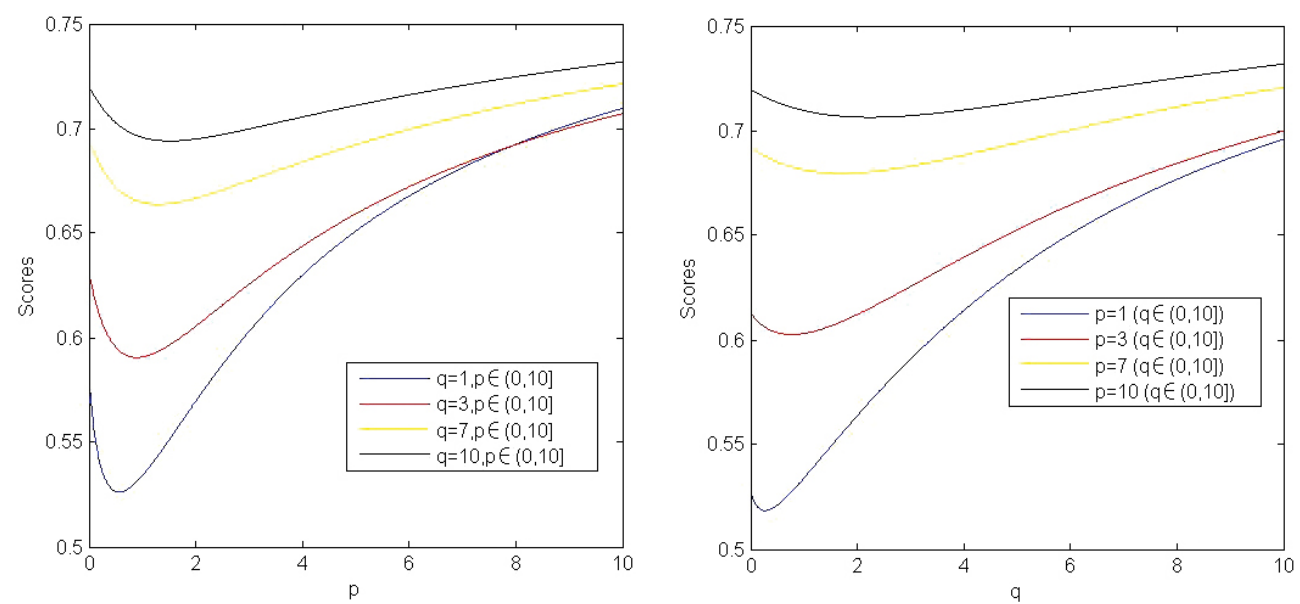

Fig. 2. Change trends of the Scores $p(q)=1,3,7,10$

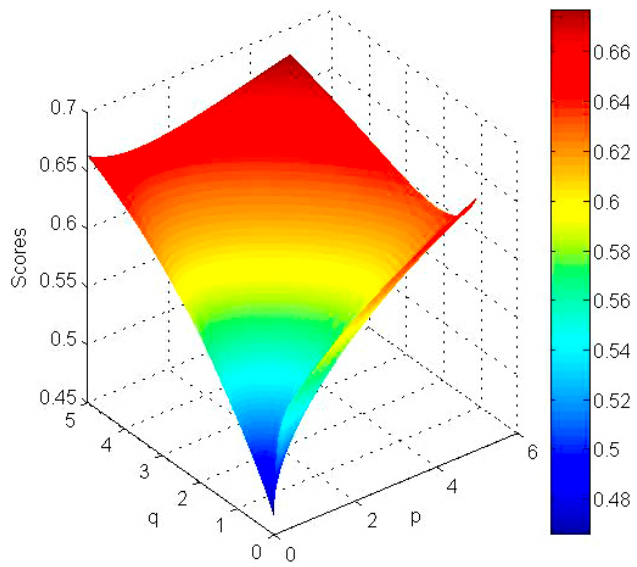

Fig. 3. Scores for HFEs obtained by the HFHM operator $(p \in[0,6], q \in[0,6])$ 
Especially, if $p=q=\frac{1}{2}$, then the HFGHM operator reduces to the Basic hesitant fuzzy geometric Heronian mean operator (BHFGHM):

$$
\operatorname{BHFGHM}\left(h_{1}, h_{2}, \cdots, h_{n}\right)=\bigotimes_{i=1, j=i}^{n}\left(\frac{1}{2}\left(h_{i} \oplus h_{j}\right)\right)^{2 / n(n+1)} .
$$

Theorem 2. Suppose there are two parameters $p$ and $q(p>0, q>0)$, and $h_{j}(i=1,2, \ldots, n)$ be a set of HFEs, then the aggregated value by using the HFGHM is as follows:

$\operatorname{HFGHM}\left(h_{1}, h_{2}, \cdots, h_{n}\right)=\bigcup_{\xi_{i} \in h_{i}, \xi_{j} \in h_{j}}\left\{1-\left(1-\prod_{i=1, j=i}^{n}\left(1-\left(1-\xi_{i}\right)^{p}\left(1-\xi_{j}\right)^{q}\right)^{\frac{2}{n(n+1)}}\right)^{\frac{1}{p+q}}\right\}$.

Proof. According to the operations defined in Definition 2, we know, $\lambda f=\bigcup_{\xi \in f}\left\{1-(1-\xi)^{\lambda}\right\}$

and

$$
p h_{i}=\bigcup_{\xi_{i} \in h_{i}}\left\{1-\left(1-\xi_{i}\right)^{p}\right\}, p h_{j}=\bigcup_{\xi_{j} \in h_{j}}\left\{1-\left(1-\xi_{j}\right)^{p}\right\}
$$

$$
h_{i} p \oplus h_{j}^{q}=\bigcup_{\xi_{i} \in h_{i}, \xi_{j} \in h_{j}}\left\{1-\left(1-\xi_{i}\right)^{p}\left(1-\xi_{j}\right)^{q}\right\} .
$$

Then:

Therefore:

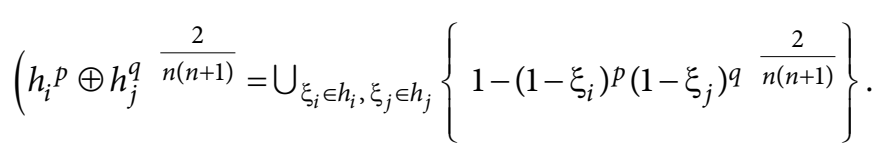

$$
\begin{aligned}
& \frac{1}{p+q}\left(\underset{i=1, j=i}{\otimes}\left(p h_{i} \oplus q h_{j}\right)^{2 / n(n+1)}\right)= \\
& \bigcup_{\xi_{i} \in h_{i}, \xi_{j} \in h_{j}}\left\{1-\left(1-\prod_{i=1, j=i}^{n}\left(1-\left(1-\xi_{i}\right)^{p}\left(1-\xi_{j}\right)^{q} \frac{2}{n(n+1)}\right)^{\frac{1}{p+q}}\right\},\right.
\end{aligned}
$$

which completes the proof of Theorem 2 .

When the parameters $p$ and $q$ take different values, some special cases of the HFGHM can be calculated as follows:

Case 1. If $p=q=\frac{1}{2}$, then the HFGHM reduces to:

$$
\operatorname{HFGHM}\left(h_{1}, h_{2}, \ldots, h_{n}\right)=\bigcup_{\xi_{i} \in h_{i}, \xi_{j} \in h_{j}}\left\{\prod_{i=1, j=i}^{n}\left(1-\sqrt{\left(1-\xi_{i}\right)\left(1-\xi_{j}\right)} \frac{2}{n(n+1)}\right\},\right.
$$

which we call the Basic hesitant fuzzy geometric Heronian mean operator (BHFGHM).

Case 2. If $q \rightarrow 0$ then the HFGHM operator reduces to:

$\lim _{q \rightarrow 0} \operatorname{HFGHM}\left(h_{1}, h_{2}, \ldots, h_{n}\right)=\frac{1}{p}\left(\sum_{i=1}^{n}\left(p h_{i} \frac{1}{n}\right)=\bigcup_{\xi_{i} \in h_{i}}\left\{1-\left(1-\prod_{i=1}^{n}\left(1-\left(1-\xi_{i}\right)^{p \frac{1}{n}}\right)^{\frac{1}{p}}\right\}\right.\right.$,

which is the GHFWG studied by Xia and $\mathrm{Xu}$ (2011b). 
Case 3. If $p=1, q \rightarrow 0$, then the HFGHM reduces to:

$$
\operatorname{HFGHM}\left(h_{1}, h_{2}, \ldots, h_{n}\right)=\left(\sum_{i=1}^{n}\left(h_{i}\right)^{\frac{1}{n}}\right)=\bigcup_{\xi_{i} \in h_{i}}\left\{\prod_{i=1}^{n}\left(\xi_{i}\right)^{\frac{1}{n}}\right\},
$$

which is the HFGM studied by Xia and Xu (2011b).

Example 2. Let $h_{1}=\{0.1,0.2,0.3\}, h_{2}=\{0.8\}, h_{3}=\{0.4,0.5\}$ be three HFEs, then by Definition 6 and Theorem 2, when the parameters take different values, the aggregated HFEs can be calculated, for example:

When $p=1, q=1, \operatorname{HFGHM}\left(h_{1}, h_{2}, h_{3}\right)=\{0.3533,0.3817,0.4196,0.4522,0.4694,0.5047\}$, and the score of the HFE is 0.4301 .

When $p=3, q=7, \operatorname{HFGHM}\left(h_{1}, h_{2}, h_{3}\right)=\{0.2301,0.2335,0.3169,0.3252,0.3877,0.4069\}$, and the score of the HFE is 0.3167 .

When $p=10, q=10, \operatorname{HFGHM}\left(h_{1}, h_{2}, h_{3}\right)=\{0.1743,0.1748,0.2663,0.2680,0.3525,0.3588\}$, and the score of the HFE is 0.2658 .

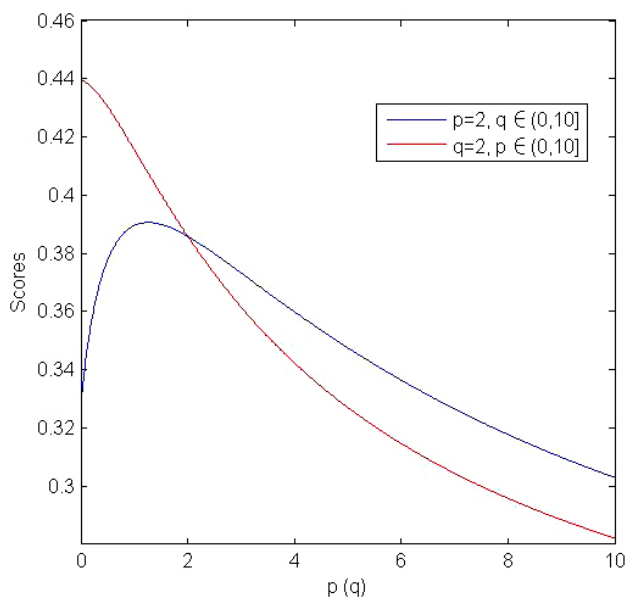

Fig. 4. Change trends of the Scores $p=2$ and $q=2$
If we let the value of one parameters fixed, take $p=2$ and $q=2$ for example, the change trends of scores of the aggregated HFEs obtained by HFGHM are shown in Figure 4.

On the other hand, Figure 5 described the change trends of scores obtained by HFGHM operator when one of the two parameters getting bigger slowly.

Different scores of the HFEs aggregated by HFGHM can be calculated as the parameters $p$ and $q$ changed. Figure 6 illustrates the scores obtained by the HFGHM operator in detail.
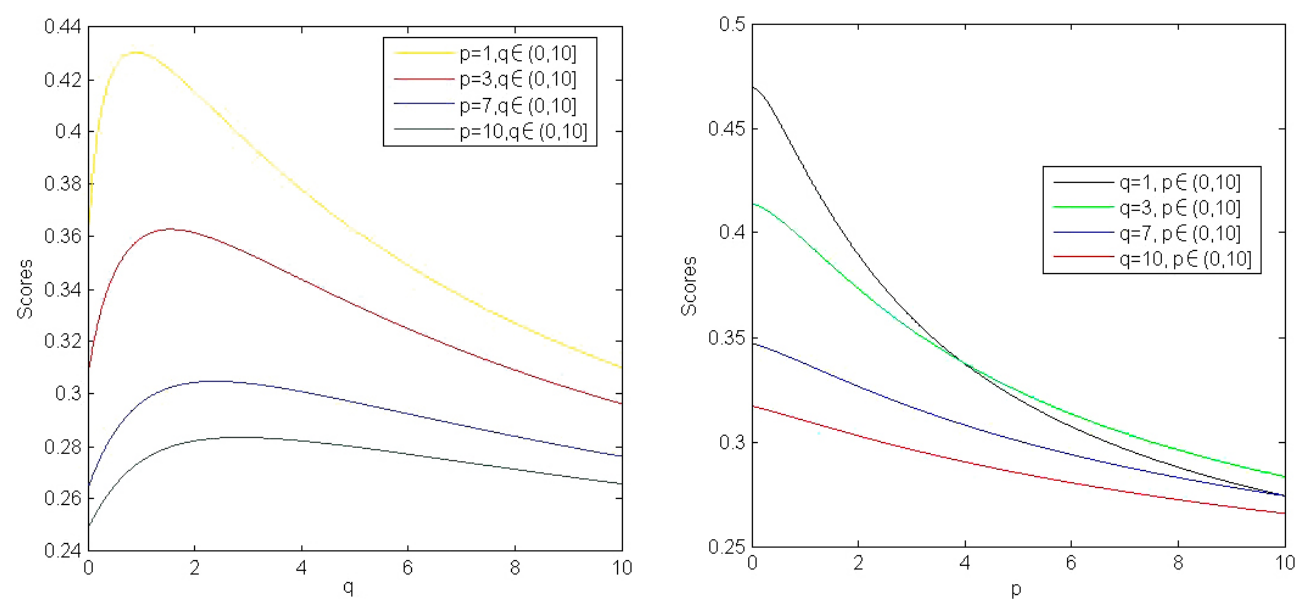

Fig. 5. Change trends of the Scores $p(q)=1,3,7,10$ 


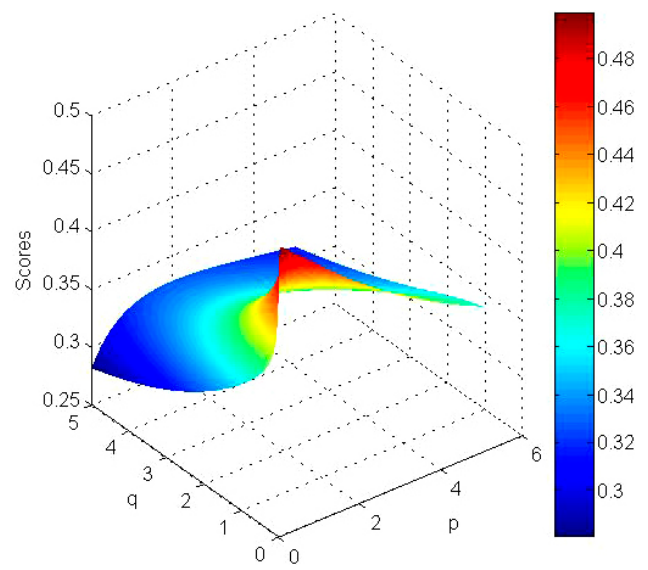

Fig. 6. Scores for HFEs obtained by the HFGHM operator $(p \in[0,6], q \in[0,6])$

\section{Hesitant fuzzy MCDM based on weighted Heronian mean operators}

HFHM and HFGHM operators can cope with the correlated hesitant fuzzy information. However, they neglected different weights of the aggregated arguments which are not feasible. In this section, the weighted forms of HFHM and HFGHM operators are studied and the hesitant fuzzy weighted Heronian mean operator (HFWHM) and hesitant fuzzy weighted geometric Heronian mean operator (HFWGHM) are proposed. Furthermore, a MCDM method based on the HFWHM and HFWGHM operators are introduced.

Definition 7. Let $h_{j}(i=1,2, \ldots, n)$ be a collection of HFEs whose weight vector is $w=\left(w_{1}, w_{2}, \ldots, w_{n}\right)^{T}$, which satisfies $w_{i}>0, i=1,2, \ldots, n$ and $\sum_{i=1}^{n} w_{i}=1$. If

$$
\begin{aligned}
& \operatorname{HFWHM}\left(h_{1}, h_{2}, \cdots, h_{n}\right)=\left(\frac{2}{n(n+1)} \sum_{i=1}^{n} \sum_{j=i}^{n}\left(w_{i} h_{i}\right)^{p} \otimes\left(w_{j} h_{j}\right)^{p}\right)^{1 / p+q} ; \\
& \operatorname{HFWGHM}\left(h_{1}, h_{2}, \ldots, h_{n}\right)=\frac{1}{p+q}\left(\underset{i=1, j=i}{\otimes}\left(\left(p h_{i}\right)^{w_{i}} \oplus\left(q h_{j}\right)^{w_{j}}\right)^{2 / n(n+1)}\right) .
\end{aligned}
$$

Then HFWHM is called the weighted HFHM (HFWHM) and HFWGHM is called the weighted HFGHM (HFWGHM).

Learned from the Theorems 1 and 2, the following research results can be got easily. Therefore, we omit the detailed proof.

Theorem 3. Let $p, q>0$, and $h_{j}(i=1,2, \ldots, n)$ be a collection of HFEs whose weight vector is $w=\left(w_{1}, w_{2}, \ldots, w_{n}\right)^{T}$, which satisfies $w_{i}>0, i=1,2, \ldots, n$ and $\sum_{i=1}^{n} w_{i}=1$. Then the aggregated
HFEs by using the HFWHM or HFWGHM is as follows:

$$
\operatorname{HFWHM}\left(h_{1}, h_{2}, \cdots, h_{n}\right)=
$$




$$
\bigcup_{\xi_{i} \in h_{i}, \xi_{j} \in h_{j}}\left\{\left(1-\prod_{i=1, j=i}^{n}\left(1-\left(1-\left(1-\xi_{i}\right)^{w_{i}}\right)^{p}\left(1-\left(1-\xi_{j}\right)^{w_{j}}\right)^{q}\right)^{\frac{2}{n(n+1)}}\right)^{\frac{1}{p+q}}\right\}
$$

$\operatorname{HFWGHM}\left(h_{1}, h_{2}, \cdots, h_{n}\right)=$

$$
\bigcup_{\xi_{i} \in h_{i}, \xi_{j} \in h_{j}}\left\{1-\left(1-\prod_{i=1, j=i}^{n}\left(1-\left(1-\xi_{i}^{w_{i}}\right)^{p}\left(1-\xi_{j}^{w_{j}}\right)^{q}\right)^{\frac{2}{n(n+1)}}\right)^{\frac{1}{p+q}}\right\} \text {. }
$$

For a MCDM problem (Liu 2014; Wang, Liu 2012; Li, Wan 2013), suppose there are $m$ alternatives to be evaluated and $C=\left\{c_{1}, c_{2}, \ldots, c_{n}\right\}$ is a set of criteria with the weight vector $w=\left(w_{1}, w_{2}, \ldots, w_{n}\right)^{T}$. The MCDM matrix is illustrated as follows (Table 1).

Table 1 . The decision matrix

\begin{tabular}{ccccc}
\hline & $\mathrm{C}_{1}$ & $C_{2}$ & $\ldots$ & $C_{n}$ \\
\hline$X_{1}$ & $h_{11}$ & $h_{12}$ & $\ldots$. & $h_{1 n}$ \\
\hline$X_{2}$ & $h_{21}$ & $h_{22}$ & $\ldots$. & $h_{2 n}$ \\
\hline$\ldots$ & $\ldots$ & $\ldots$ & $\ldots$ & $\ldots$ \\
\hline$X_{m}$ & $h_{m 1}$ & $h_{m 2}$ & $\ldots$. & $\mathrm{h}_{\mathrm{mn}}$ \\
\hline
\end{tabular}

In the decision making matrix, $h_{i j}$ is the performance of criteria $C_{j}$ regarding alternative $x_{i}$ expressed by experts. The main decision processes are shown as follows.

Step 1. Fuse all the HFEs $h_{i j}(i=1,2, \ldots, n)$ of the $i$ th line, and gain the overall HFEs $h_{i}$ regard to the alternative $A_{i}$ by the HFWHM or HFWGHM operators.

Step 2. Rank the hesitant fuzzy values $h_{i}(i=1,2, \ldots, m)$ and select the most appropriate one.

In the following, we show a practical application of the proposed methodology by considering a dormitory construction projection selection problem in a real company concerning MCDM.

In order to support company's future development, $\mathrm{ABC}$ Company plan to have a new plant C in D city. According to the Headcount Plan, Plant C needs to recruit 4000 employees in the following two years, it's a really hard work. Below are the existing transportation conditions for plant C:

1) Plant $C$ located in the outskirts of the city $D$, the distance between the company and city downtown is about 2-hour drive.

2) The distance between the company and the airport is about 1-hour drive.

3) There is only one bus - bus runs from the nearest living zone to the company, which runs 45 minutes between each run. The earliest bus is $7 \mathrm{am}$, and the latest is $6 \mathrm{pm}$.

4) Because of the remote location, taxis are barely available, and thus, if someone needs to go out in emergency, he can only drive by himself. 
Above poor transportation conditions increased the recruiting difficulties of plant $\mathrm{C}$, many candidates rejected the offer due to the inconvenient. Thus except to enlarge recruiting channel, Building employees' dormitory is another effectively way to attract candidates and also will acting an important role to the employee retention project in the future. Actually, whether dormitory will be provided has become one of the key factors in the hiring process since living cost in city $\mathrm{D}$ is very high, especially when hiring blue - collar workers.

Based on above reasons, Plant $\mathrm{C}$ raised dormitory construction proposal after fully comparison and analysis and it is now at the bidding stage. There are 4 suppliers to bid for this construction project. According to related requirements, Plant $\mathrm{C}$ needs to review them from 3 points $\left(c_{1}, c_{2}, c_{3}\right.$, ) which are listed as below:

1) Qualification: supplier should have required qualification, including registered capital and its finical background. This dormitory project need the vendor to bear all the finical risk, thus the vendor should have strong financial resources $\left(c_{1}\right)$.

2) Cost: supplier' bidding price is the most important point since cost always acting a very important role in a manufacturing plant $\left(c_{2}\right)$.

3) Similar experiences: it's better for supplier to have experiences to complete a similar project $\left(c_{3}\right)$. Since this project is a big one, previous experiences can help this dormitory project smoothly completed.

Assume the weight of the three criteria is $(0.3,0.4,0.3)^{T}$. Three experts are invited to evaluate the four vendors and the hesitant fuzzy decision making matrix are shown in Table 2.

Table 2. The hesitant fuzzy decision matrix

\begin{tabular}{cccc}
\hline & $C_{1}$ & $C_{2}$ & $C_{3}$ \\
\hline$X_{1}$ & $\{0.7,0.8\}$ & $\{0.6,0.7,0.8\}$ & $\{0.8\}$ \\
\hline$X_{2}$ & $\{0.4,0.6\}$ & $\{0.5\}$ & $\{0.3,0.4\}$ \\
\hline$X_{3}$ & $\{0.6\}$ & $\{0.5,0.7\}$ & $\{0.6,0.7,0.8\}$ \\
\hline$X_{4}$ & $\{0.3,0.4,0.5\}$ & $\{0.4,0.6,0.7\}$ & $\{0.5\}$ \\
\hline
\end{tabular}

Take $h_{31}=\{0.6\}$ for example, it means the three experts expressed the same views on the performance of alternative $X_{3}$ on criterion $C_{1}$ and the value is 0.6 . Therefore, the evaluation of alternative $X_{3}$ on criterion $C_{1}$ is expressed by HFE $\{0.6\}$. Take $h_{11}=\{0.7,0.8\}$ for another example, it means two of the three experts expressed the same views on the performance of alternative $X_{1}$ on criterion $C_{1}$ and the value is 0.7 or 0.8 . The third expert expressed 0.8 or 0.7 simultaneously. Therefore, the evaluation of alternative $X_{1}$ on criterion $C_{1}$ is expressed by HFE $\{0.7,0.8\}$.

For illustrating the influence of the parameter $p$ and $q$ in the above evaluation problem, the different value of $p$ and $q$ are taken to aggregate the HFE and the ultimate results are shown in Table 3.

Furthermore, let $p$ or $q$ fixed, the change trends of the scores of four alternatives are shown in Figures 7 and 8. 
Table 3. Score obtained by the HFWHM operator and the rankings results

\begin{tabular}{llrrrrc}
\hline & Operators & $A_{1}$ & $A_{2}$ & $A_{3}$ & $A_{4}$ & Ranking \\
\hline$p=0, q=1$ & HFWHM & 0.3792 & 0.1756 & 0.3004 & 0.2182 & $A_{1} \succ A_{3} \succ A_{4} \succ A_{2}$ \\
\hline$p=q=1$ & HFWHM & 0.3724 & 0.1875 & 0.2890 & 0.2117 & $A_{1} \succ A_{3} \succ A_{4} \succ A_{2}$ \\
\hline$p=q=5$ & HFWHM & 0.3829 & 0.2152 & 0.3096 & 0.2533 & $A_{1} \succ A_{3} \succ A_{4} \succ A_{2}$ \\
\hline$p=0, q=10$ & HFWHM & 0.3928 & 0.2213 & 0.3251 & 0.2674 & $A_{1} \succ A_{3} \succ A_{4} \succ A_{2}$ \\
\hline$p=10, q=10$ & HFWHM & 0.3925 & 0.2273 & 0.3237 & 0.2710 & $A_{1} \succ A_{3} \succ A_{4} \succ A_{2}$ \\
\hline
\end{tabular}

As we can see from Table 3 and Figures 7 and 8, the ranking results are the same though different parameter values of $p$ and $q$ are taken. In other words, the MCDM method based on HFWHM operator offers good stability. Different scores of the HFEs aggregated by HFWHM can be calculated as the parameters $p$ and $q$ changed. Figure 9 illustrates the scores obtained by the HFWHM operator in detail.
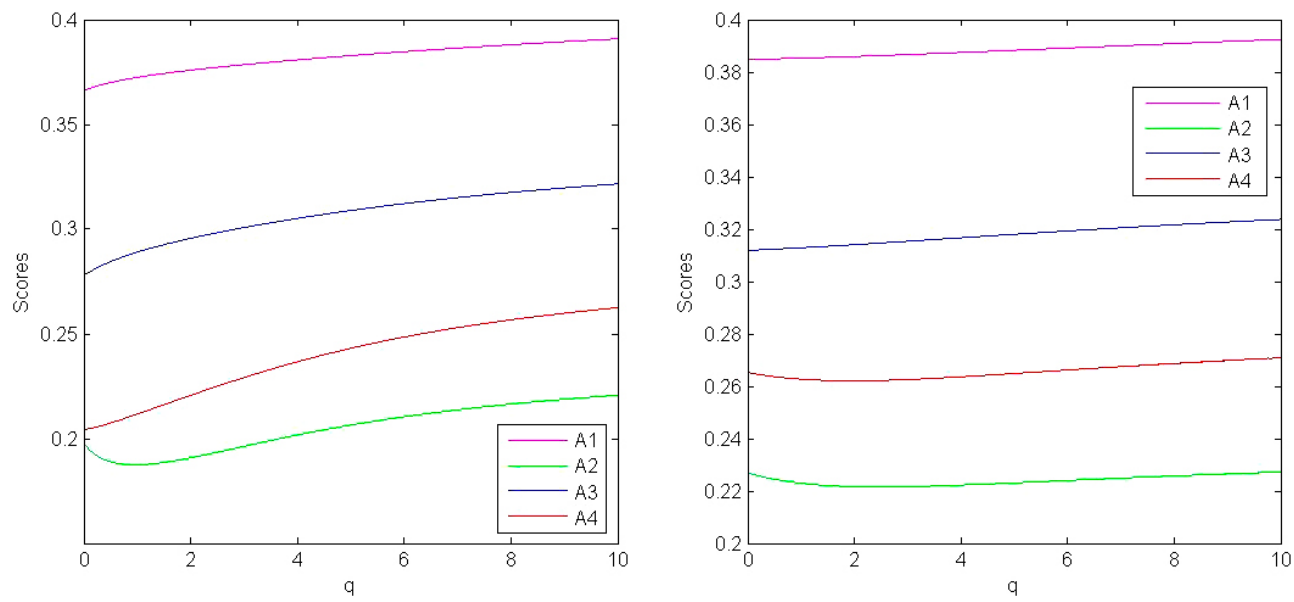

Fig. 7. Scores of four alternatives $(p \in(0,10] ; p=1, p=10)$
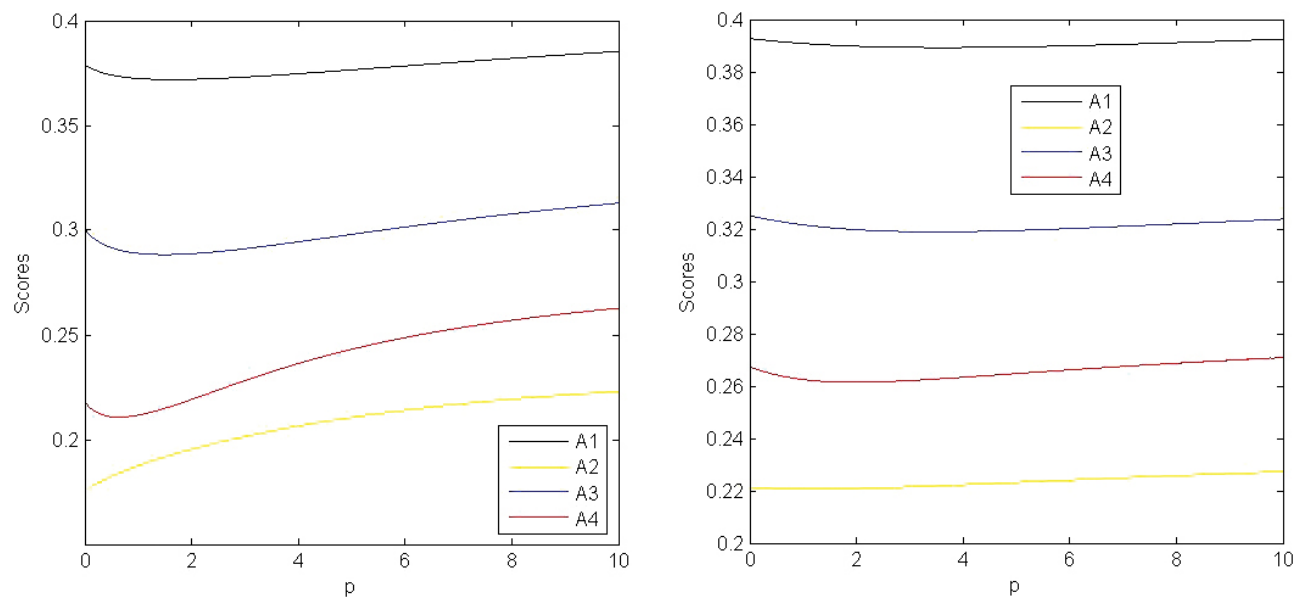

Fig. 8. Scores of four alternatives $(p \in(0,10] ; q=1, q=10)$ 

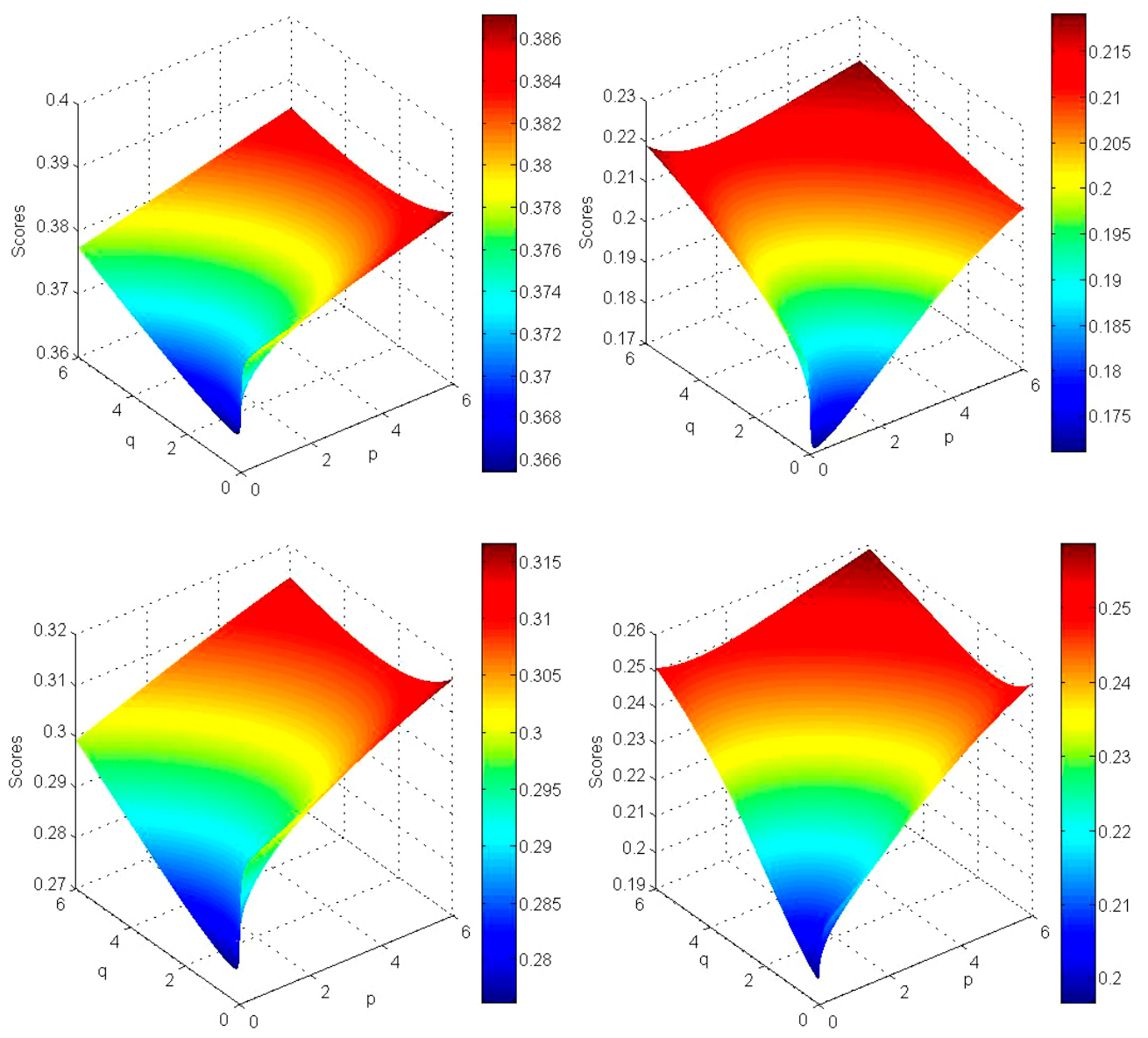

Fig. 9. Scores obtained by the HFWHM operator $(p \in[0,6], q \in[0,6])$

About the hesitant fuzzy MCDM method, we can compare with the method based on HFWGHM operator, HFWBM operator (Zhu, Xu 2013b) and HFWGBM operator (Zhu et al. 2012). For illustrating the influence of the parameters $p$ and $q$ in the HFWGHM, HFWBM, and HFWGBM operators based methods, the different value of $p$ and $q$ are taken to aggregate the HFE and the ultimate results are shown in Table 4.

Let $q$ fixed, the variation tendency of the scores of the four alternatives based on the HFWGHM operator, HFWBM operator and HFWGBM operator are shown as follows.

Obviously, the ranking results of the hesitant fuzzy MCDM methods based on four different aggregation operators have hardly changed. From the Figures 7-8 and 10-12, we can clearly see that the ranking results of the four alternatives and the gaps between each other. Different scores of the HFEs aggregated by HFWGHM, HFWBM, and HFWGBM can be calculated as the parameters $p$ and $q$ changed. Figures 13-15 illustrate the details. 
Table 4. Score obtained by the HFWGHM, HFWBM, HFWGBM operators and ranking results

\begin{tabular}{llccccc}
\hline & Operators & $A_{1}$ & $A_{2}$ & $A_{3}$ & $A_{4}$ & Ranking \\
\hline$p=0, q=1$ & HFWBM & 0.1767 & 0.0790 & 0.1381 & 0.0876 & $A_{1} \succ A_{3} \succ A_{4} \succ A_{2}$ \\
\cline { 2 - 7 } & HFWGHM & 0.9082 & 0.7506 & 0.8610 & 0.7949 & $A_{1} \succ A_{3} \succ A_{4} \succ A_{2}$ \\
\cline { 2 - 7 } & HFWGBM & 0.9307 & 0.8326 & 0.8971 & 0.8423 & $A_{1} \succ A_{3} \succ A_{4} \succ A_{2}$ \\
\hline$p=q=1$ & HFWBM & 0.2388 & 0.1216 & 0.1809 & 0.1226 & $A_{1} \succ A_{3} \succ A_{4} \succ A_{2}$ \\
\cline { 2 - 7 } & HFWGHM & 0.9043 & 0.7637 & 0.8539 & 0.7852 & $A_{1} \succ A_{3} \succ A_{4} \succ A_{2}$ \\
\cline { 2 - 7 } & HFWGBM & 0.9225 & 0.8168 & 0.8836 & 0.8206 & $A_{1} \succ A_{3} \succ A_{4} \succ A_{2}$ \\
\hline$p=q=5$ & HFWBM & 0.3302 & 0.1816 & 0.2555 & 0.1832 & $A_{1} \succ A_{3} \succ A_{4} \succ A_{2}$ \\
\cline { 2 - 7 } & HFWGHM & 0.8831 & 0.7497 & 0.8313 & 0.7651 & $A_{1} \succ A_{3} \succ A_{4} \succ A_{2}$ \\
\cline { 2 - 7 } & HFWGBM & 0.8952 & 0.7752 & 0.8535 & 0.7685 & $A_{1} \succ A_{3} \succ A_{4} \succ A_{2}$ \\
\hline$p=0, q=10$ & HFWBM & 0.3378 & 0.2025 & 0.2830 & 0.1718 & $A_{1} \succ A_{3} \succ A_{4} \succ A_{2}$ \\
\cline { 2 - 7 } & HFWGHM & 0.8775 & 0.7380 & 0.8256 & 0.7637 & $A_{1} \succ A_{3} \succ A_{4} \succ A_{2}$ \\
\cline { 2 - 7 } & HFWGBM & 0.8455 & 0.7475 & 0.8311 & 0.7375 & $A_{1} \succ A_{3} \succ A_{4} \succ A_{2}$ \\
\hline$p=10, q=10$ & HFWBM & 0.3492 & 0.1967 & 0.2717 & 0.1661 & $A_{1} \succ A_{3} \succ A_{4} \succ A_{2}$ \\
\cline { 2 - 6 } & HFWGHM & 0.9439 & 0.7418 & 0.8893 & 0.7528 & $A_{1} \succ A_{3} \succ A_{4} \succ A_{2}$ \\
\cline { 2 - 6 } & HFWGBM & 1.0000 & 0.7643 & 0.9126 & 0.7509 & $A_{1} \succ A_{3} \succ A_{4} \succ A_{2}$ \\
\hline
\end{tabular}
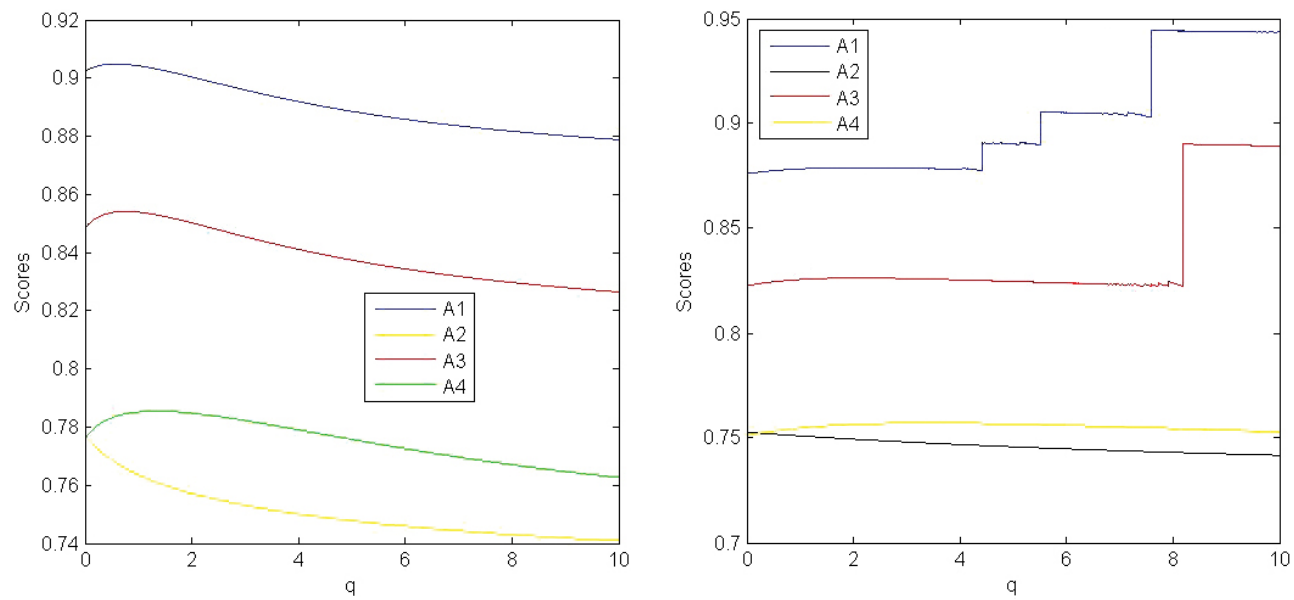

Fig. 10. Results based on HFWGHM operator $(q \in(0,10] ; p=1, p=10)$ 

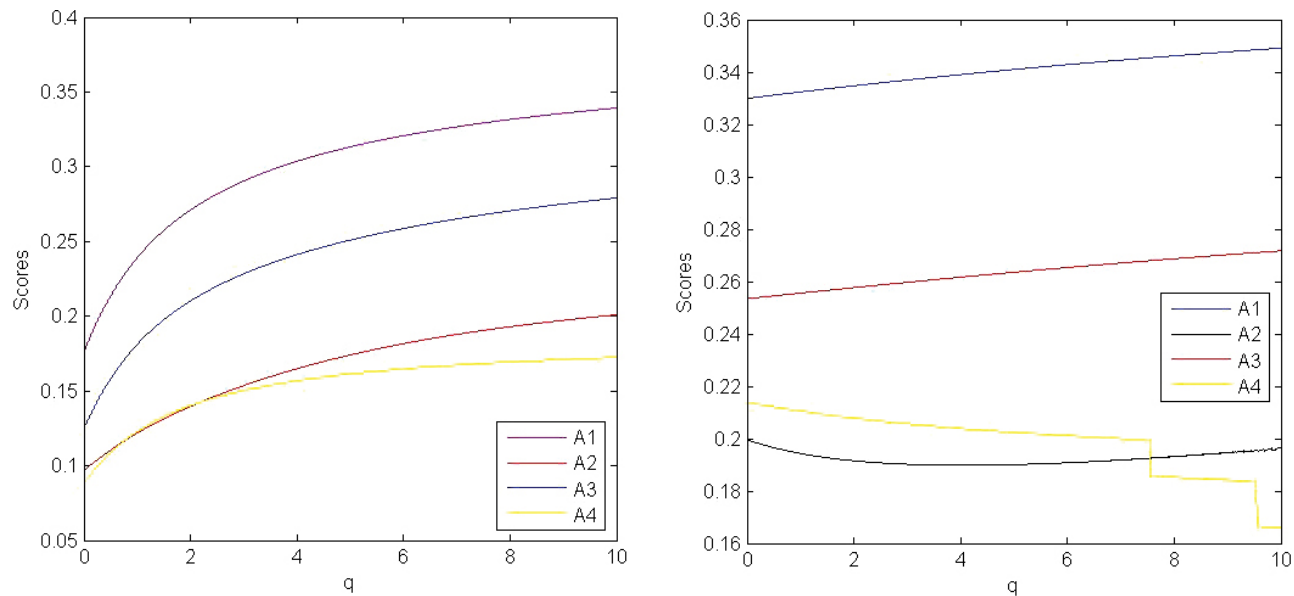

Fig. 11. Results based on HFWBM operator $(q \in(0,10] ; p=1, p=10)$
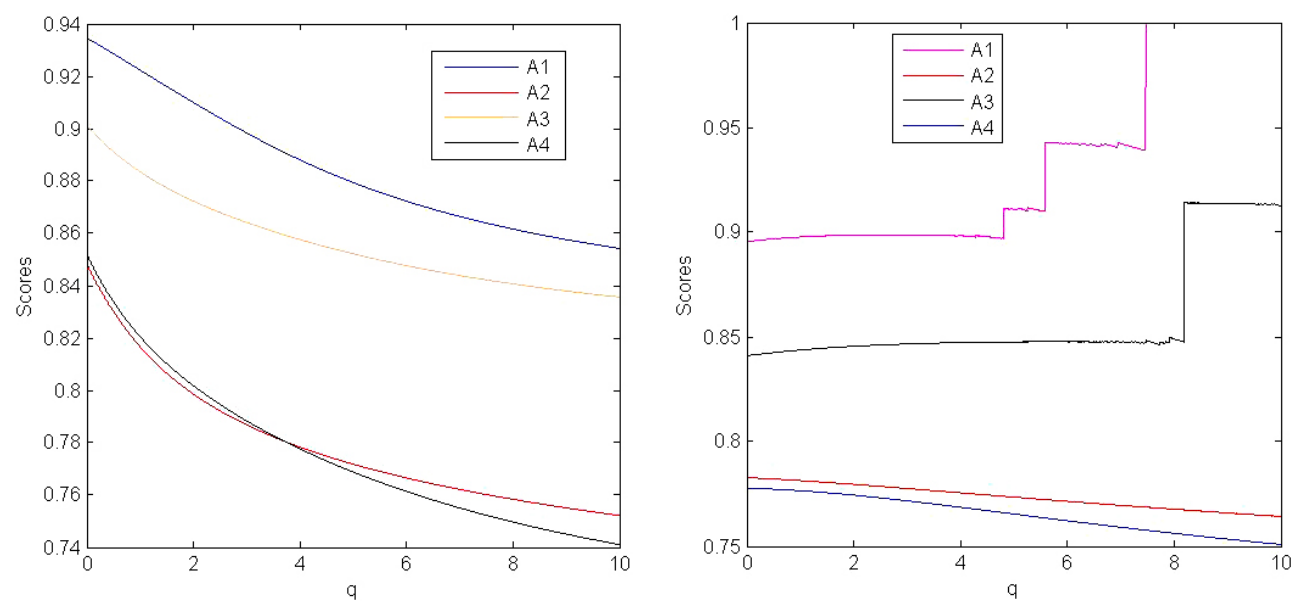

Fig. 12. Results based on HFWGBM operator $(p \in(0,10] ; p=1, p=10)$ 

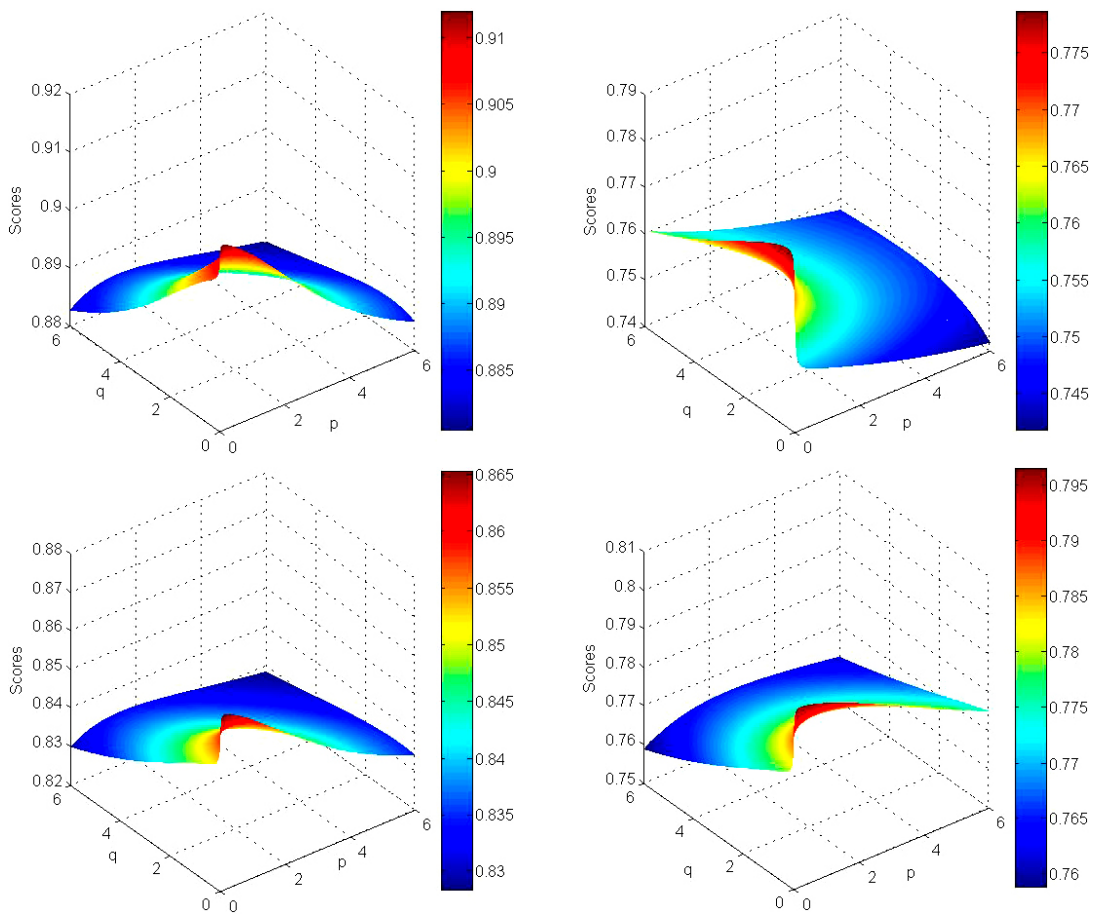

Fig. 13. Scores obtained by the HFWGHM operator $(p \in[0,6], q \in[0,6])$
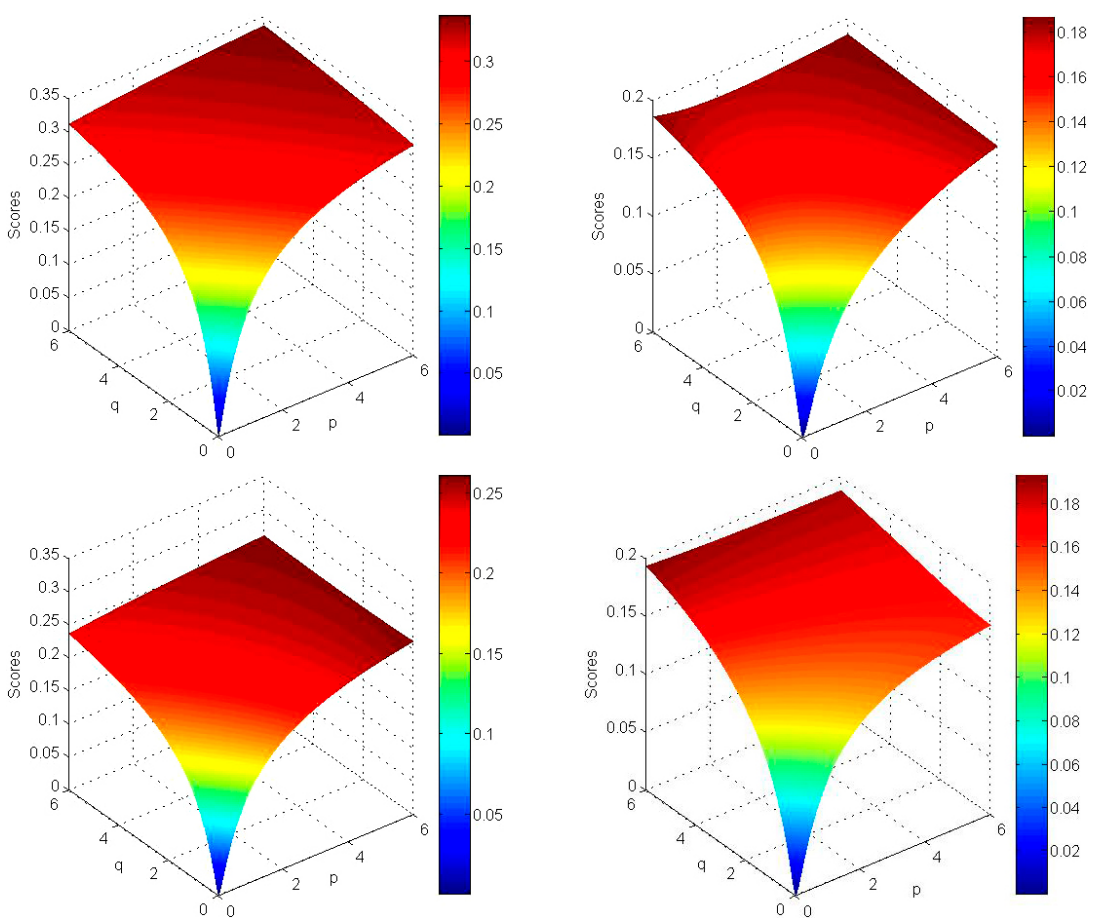

Fig. 14. Scores obtained by the HFWBM operator $(p \in[0,6], q \in[0,6])$ 

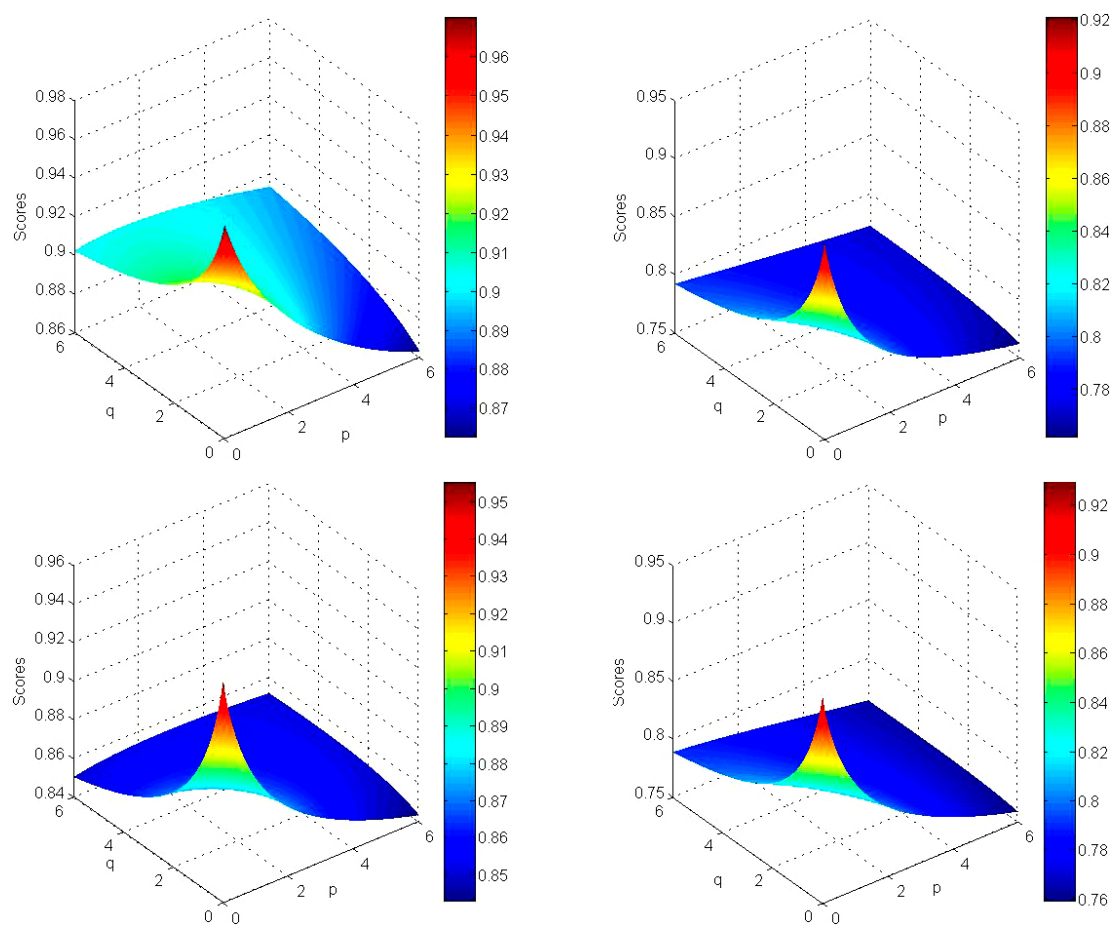

Fig. 15. Scores obtained by the HFWGBM operator $(p \in[0,6], q \in[0,6])$

\section{Conclusions}

In this paper, we have researched new hesitant fuzzy MCDM methods, and we have applied them in dormitory construction projection selection problem. We have put forwarded some operators for HFEs, such as HFHM, HFGHM, HFWHM and HFWGHM operators. We have proved that some common operators, such as HFWA, HFWG, GHFWA and GHFWG operators are some exceptions of the operators put forwarded in this paper. In other words, the Heronian mean operators are more flexible and general. Further, the comparison with other MCDM methods based on HFWBM, HFWGBM operators are also provided. We have forwarded the proposed methods to the selection of dormitory construction projection, but it should be noted that they can also be applied to other evaluation problems, such as the personnel evaluation, investment plans evaluations, and so on. In future research, we will focus on how these methods proposed in this paper can be applied to other evaluation fields, and we will consider other types of HFHMs.

\section{Acknowledgements}

The authors wish to thank the anonymous reviewers for their constructive comments on this study. This work has been supported by China National Natural Science Foundation (No. 71301142), Zhejiang Science \& Technology Plan of China (2015C33024), Zhejiang 
Provincial Natural Science Foundation of China (No. LQ13G010004), Project Funded by China Postdoctoral Science Foundation (No. 2014M550353) and the National Education Information Technology Research (No. 146242069).

\section{References}

Atanassov, K. T. 1986. Intuitionistic fuzzy sets, Fuzzy Sets and Systems 20(1): 87-96. http://dx.doi.org/10.1016/S0165-0114(86)80034-3

Beliakov, G.; Pradera, A.; Calvo, T. 2007. Aggregation functions: a guide for practitioners. Berlin: Springer.

Farhadinia, B. 2013. Information measures for hesitant fuzzy sets, Information Sciences 240: 129-144. http://dx.doi.org/10.1016/j.ins.2013.03.034

Bonferroni, C. 1950. Sulle medie multiple di potenze, Bolletino Matematica Italiana 5: 267-270.

Chen, N.; Xu, Z. S.; Xia, M. M. 2013. Interval-valued hesitant preference relations and their applications to group decision making, Knowledge-Based Systems 37: 528-540.

http://dx.doi.org/10.1016/j.knosys.2012.09.009

Dubois, D.; Prade, H. 1980. Fuzzy sets and systems: theory and applications. New York: Academic Press.

Karsak, E. E.; Dursun, M. 2015. An integrated fuzzy MCDM approach for supplier evaluation and selection, Computers \& Industrial Engineering 82: 82-93. http://dx.doi.org/10.1016/j.cie.2015.01.019

Li, D. F.; Wan, S. P. 2013. Fuzzy linear programming approach to multiattribute decision making with multiple types of attribute values and incomplete weight information, Applied Soft Computing 13(11): 4333-4348. http://dx.doi.org/10.1016/j.asoc.2013.06.019

Liao, H. C.; Xu, Z. S.; Xia, M. M. 2014. Multiplicative consistency of hesitant fuzzy preference relation and its application in group decision making, International Journal of Information Technology \& Decision Making 13(1): 47-76. http://dx.doi.org/10.1142/S0219622014500035

Liu, J.; Liu, P.; Liu, S. F.; Zhou, X. Z.; Zhang, T. 2015. A study of decision process in MCDM problems with large number of criteria, International Transactions in Operational Research 22(2): 237-264. http://dx.doi.org/10.1111/itor.12102

Liu, P. D. 2014. Some Hamacher aggregation operators based on the interval-valued intuitionistic fuzzy numbers and their application to group decision making, IEEE Transactions on Fuzzy Systems 22(1): 83-97. http://dx.doi.org/10.1109/TFUZZ.2013.2248736

Liu, P. D.; Jin, F. 2012. A multi-attribute group decision-making method based on weighted geometric aggregation operators of interval-valued trapezoidal fuzzy numbers, Applied Mathematical Modelling 36(6): 1498-2509. http://dx.doi.org/10.1016/j.apm.2011.09.006

Miyamoto, S. 2000. Multisets and fuzzy multisets, in Z.-Q. Liu, S. Miyamoto (Eds.). Soft computing and human-centered machines. Berlin: Springer. http://dx.doi.org/10.1007/978-4-431-67907-3_2

Miyamoto, S. 2005. Remarks on basics of fuzzy sets and fuzzy multisets, Fuzzy Sets and Systems 156(3): 427-431. http://dx.doi.org/10.1016/j.fss.2005.05.040

Quirós, P.; Alonso, P.; Bustince, H.; Díaz, I.; Montes, S. 2015. An entropy measure definition for finite interval-valued hesitant fuzzy sets, Knowledge-Based Systems 84: 121-133.

http://dx.doi.org/10.1016/j.knosys.2015.04.005

Parameshwaran, R.; Kumar, S. P.; Saravanakumar, K. 2015. An integrated fuzzy MCDM based approach for robot selection considering objective and subjective criteria, Applied Soft Computing 26: 31-41. http://dx.doi.org/10.1016/j.asoc.2014.09.025

Tan, C. Q. 2011. Generalized intuitionistic fuzzy geometric aggregation operator and its application to multi-criteria group decision making, Soft Computing 15(5): 867-876.

http://dx.doi.org/10.1007/s00500-010-0554-6 
Torra, V. 2010. Hesitant fuzzy sets, International Journal of Intelligent Systems 25(6): 529-539. http://dx.doi.org/10.1002/int.20418

Torra, V.; Narukawa, Y. 2009. On hesitant fuzzy sets and decision, in The 18th IEEE International Conference on Fuzzy Systems, 20-24 August 2009, Jeju Island, Korea, 1378-1382.

Wang, W. Z.; Liu, X. W. 2011. Intuitionistic fuzzy geometric aggregation operators based on Einstein operations, International Journal of Intelligent Systems 26(11): 1049-1075. http://dx.doi.org/10.1002/int.20498

Wang, W. Z.; Liu, X. W. 2012. Intuitionistic fuzzy information aggregation using Einstein operations, IEEE Transactions on Fuzzy Systems 20(5): 923-938. http://dx.doi.org/10.1109/TFUZZ.2012.2189405

Wei, G. W. 2010. Some induced geometric aggregation operators with intuitionistic fuzzy information and their application to group decision making, Applied Soft Computing 10(2): 423-431. http://dx.doi.org/10.1016/j.asoc.2009.08.009

Wei, G. W.; Zhao, X. F.; Wang, H. J. 2012. Hesitant fuzzy Choquet itegral aggregation operators and their applications to multiple attribute decision making, Information 15(2): 441-448.

Xia, M. M.; Xu, Z. S. 2011a. On distance and correlation measures of hesitant fuzzy information, International Journal of Intelligent Systems 26(5): 410-425. http://dx.doi.org/10.1002/int.20474

Xia, M. M.; Xu, Z. S. 2011b. Hesitant fuzzy information aggregation in decision making, International Journal of Approximate Reasoning 52(3): 395-407. http://dx.doi.org/10.1016/j.ijar.2010.09.002

Xia, M. M.; Xu, Z. S.; Chen, N. 2013. Some hesitant fuzzy aggregation operators with their application in decision making, Group Decision and Negotiation 22(2): 259-279.

http://dx.doi.org/10.1007/s10726-011-9261-7

$\mathrm{Xu}, \mathrm{Z}$. S. 2000. On consistency of the weighted geometric mean complex judgment matrix in AHP, European Journal of Operational Research 126(3): 683-687. http://dx.doi.org/10.1016/S0377-2217(99)00082-X

Xu, Z. S.; Xia, M. M. 2011. Distance and similarity measures for hesitant fuzzy sets, Information Sciences 181(11): 2128-2138. http://dx.doi.org/10.1016/j.ins.2011.01.028

Xu, Z. S.; Xia, M. M. 2012. Hesitant fuzzy entropy and cross-entropy and their use in multi-attribute decision making, International Journal of Intelligent Systems 27(9): 799-822. http://dx.doi.org/10.1002/int.21548

Xu, Z. S.; Zhang, X. L. 2013. Hesitant fuzzy multi-attribute decision making based on TOPSIS with incomplete weight information, Knowledge-Based Systems 52: 53-64. http://dx.doi.org/10.1016/j.knosys.2013.05.011

Yager, R. R. 1986. On the theory of bags, International Journal of General Systems 13(1): 23-37. http://dx.doi.org/10.1080/03081078608934952

Yu, D. J. 2012. Group decision making based on generalized intuitionistic fuzzy prioritized geometric operator, International Journal of Intelligent Systems 27(7): 635-661. http://dx.doi.org/10.1002/int.21538

Yu, D. J. 2013. Intuitionistic fuzzy geometric Heronian mean aggregation operators, Applied Soft Computing 13(2): 1235-1246. http://dx.doi.org/10.1016/j.asoc.2012.09.021

Yu, D. J.; Wu, Y. Y. 2012. Interval-valued intuitionistic fuzzy Heronian mean operators and their application in multi-criteria decision making, African Journal of Business Management 6(11): 4158-4168.

Zhang, X. L.; Xu, Z. S. 2012. An MST cluster analysis method under hesitant fuzzy environment, Control and Cybernetics 41: 645-666.

Zhu, B.; Xu, Z. S. 2013a. Regression methods for hesitant fuzzy preference relations, Technological and Economic Development of Economy 19(Supplement 1): S214-S227.

http://dx.doi.org/10.3846/20294913.2014.881430 
Zhu, B.; Xu, Z. S. 2013b. Hesitant fuzzy Bonferroni means for multi-criteria decision making, Journal of the Operational Research Society 64(12): 1831-1840. http://dx.doi.org/10.1057/jors.2013.7

Zhu, B.; Xu, Z. S. 2014. Consitency measures for hesitant fuzzy linguistic preference relations, IEEE Transactions on Fuzzy Systems 22(1): 35-45. http://dx.doi.org/10.1109/TFUZZ.2013.2245136

Zhu, B.; Xu, Z. S.; Xia, M. M. 2012. Hesitant fuzzy Geometric Bonferroni means, Information Sciences 205: 72-85. http://dx.doi.org/10.1016/j.ins.2012.01.048

Dejian YU. He received the PhD degree in management science and engineering from Southeast University, Nanjing, China, in 2012. He is currently an Associated Professor with the School of Information, Zhejiang University of Finance and Economics, Hangzhou, China. He has authored more than 20 scientific articles. His current research interests include aggregation operators, information fusion, and multi-criteria decision making. 